
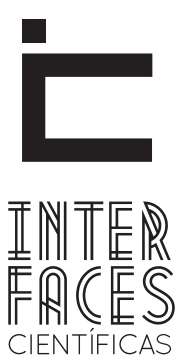

DIREITO

ISSN IMPRESSO 2316-3321

E - ISSN 2316-381X

DOI - 10.17564/2316-381X.2017v5n2p29-36

\title{
FORMAÇÃO DO FEDERALISMO NORTE-AMERICANO E DO FEDERALLSMO BRASILEIRO
}

\author{
TRAINING OF NORTH AMERICAN FEDERALISM AND BRAZILIAN FEDERALISM \\ FORMACIÓN DE FEDERALISMO NORTEAMERICANO Y FEDERALISMO BRASILEÑO
}

Júnio Mendonça de Andrade

Gustavo Santana de Jesus ${ }^{3}$
Karlos Kleiton dos Santos 2

para a formação do federalismo brasileiro, buscamos também, fazer uma análise sobre tais pontos de influência. Ainda assim, procuramos, também, fazer uma análise comparativa entre o federalismo norte-americano e o federalismo brasileiro, trazendo a baila alguns fenômenos que influenciaram diretamente para a formação do respectivo Estado, constituindo peculiaridade, traços marcantes e caracterizadores da sua forma de organização político-administrativa.

\section{PALAVRAS-CHAVE}

Forma de Estado. Idealizadores. Federalismo. Características. 


\section{ABSTRACT}

This article aims to reflect on the ideas that originated the form of federalist state, as well as reflecting on the peculiarities of American federalism and the Brazilian federalism. We started the work making a broad theme approach, analyzing the thoughts of the main precursors of federalism and the contributions each made to the training and improvement of the form of federalist state. Then, we analyze the formation of the Brazilian federalism, making an analysis of all the constitutions that Brazil already possessed with the aim to observe the constitution from which Brazil has adopted the form of a federalist state. Given the influence that American

\section{RESUMEN}

Este artículo tiene como objetivo reflexionar sobre las ideas que dieron origen a la forma de Estado federal, así como reflexionar sobre las peculiaridades del federalismo americano y el federalismo brasileño. Empezamos el trabajo de hacer un enfoque amplio tema, analizando los pensamientos de los principales precursores del federalismo y las contribuciones hechas cada una a la formación y la mejora de la forma de Estado federal. A continuación se analiza la formación del federalismo brasileño, haciendo un análisis de todas las constituciones que Brasil ya poseía con el objetivo de observar la constitución de la que Brasil ha adoptado la forma de un estado federal. Dada la influencia que el federalismo estadounidense tenía federalism had to the formation of Brazilian federalism, we seek also to an analysis of these points of influence. Still, we try also to make a comparative analysis of the American federalism and the Brazilian federalism, bringing to the fore some phenomena influencing directly to the formation of the State, providing peculiarity, distinctive features and characterizing their form of political-administrative organization.

\section{KEYWORDS}

Government form. Creators. Federalism. Features. a la formación del federalismo brasileño, buscamos también a un análisis de estos puntos de influencia. Aún así, tratamos también de hacer un análisis comparativo del federalismo americano y el federalismo brasileño, haciendo hincapié en algunos fenómenos que influyen directamente en la formación del Estado, proporcionando peculiaridad, rasgos distintivos que caracterizan y su forma de organización política -administrativa.

\section{PALABRAS CLAVE}

forma de gobierno, creadores, características del federalismo. 


\section{INTRODUCC̆̃O}

Apesar de não ter sua origem nos Estados Unidos da América, os precursores na formação do Federalismo mundial foram pensadores estadunidenses, principalmente os idealizadores da obra The Federalist. Após se tornar independente da Inglaterra, as treze colônias formaram por meio de um Pacto, formaram uma Confederação, por meio do documento que ficou conhecido como Articles of Confederation.

Após influência dos textos publicados nos jornais americanos, que ficou conhecido como The Federalist (1787-1788), escrito por Alexander Hamilton, James Madison e John Jay, foi instaurada uma Federação, já que a Confederação não garantia a paz interna, em suma, não tinha um poder unificado que conseguisse dirigir o país do ponto de vista interno.

Em outro momento da História, o Brasil, após se tornar independente de Portugal, precisava encontrar um modelo de Estado capaz de suprir as necessidades do país e principalmente as necessidades dos cidadãos. Partindo do modelo norte-americano, foi que - Brasil instaurou a Federação pela primeira vez, por meio da Constituição de 1891, não mais deixando de adotar tal modelo nas Constituições seguintes. Assim, atualmente o Brasil é uma Federação, conforme estabelecido pela Constituição Federal de 1988. Mesmo sendo baseada no modelo americano, a Federação brasileira tem peculiaridades que the são próprias.

É indiscutível que a maneira pela qual o Estado organiza seu território e estrutura o seu poder político depende da natureza e da história de cada país. A forma de organização do Estado - se unitário, federado ou confederado - reflete na repartição de competências, que leva em consideração a composição geral do país, a estrutura do poder, sua unidade, distribuição e competências no respectivo território.

Dentro desse contexto, questiona-se: onde se materializou pela primeira vez os ideais da forma de Estado Federalista? Como tal ideia chegou e criou força nos Estados Unidos da América? Qual a influência do Federalismo americano para que ocorresse a instau- ração do federalismo no Brasil? Quais as peculiaridades do federalismo americano e brasileiro?

Assim sendo, o presente estudo tem como objetivo analisar o surgimento do Federalismo no mundo e ao mesmo tempo verificar as peculiaridades do federalismo norte-americano e brasileiro e a influência do primeiro no último, já que aquele foi a principal base para a formação da teoria do Estado Moderno.

Justifica-se a pesquisa, pois a Federação está presente no Brasil desde sua instauração em 1891. Além de ser muito importante para a convivência e paz social, uma vez que o exercício das liberdades individuais está diretamente ligado ao modo de como o poder está dividido no território nacional. E, para a elaboração do presente artigo foram utilizadas referências documentais, tais como, livros, artigos e monografias da área do Direito Constitucional e da Ciência Política.

\section{SURGIMENTO DO FEDERALISMO}

O primeiro a tratar do Estado Federal nos Estados Unidos foi o escritor americano Calhoun, no século XIX. Interpretando o presente autor, Azambuja (2005, p. 372), diz que é característica essencial do Estado a soberania que somente pode pertencer à união ou aos Estados-membros, jamais a ambos ao mesmo tempo. Assim sendo, caso a soberania pertença aos Estados-membros, estaríamos diante de uma Confederação. Caso pertença à união, as unidades federativas não são Estados e estaríamos diante de um Estado simples. Apesar de difundida na Europa, esta teoria enfrentou fortes resistências, por isso, não foi aceita como modelo.

Contrário à tese defendida por Calhoun, surgiu a Teoria de Le Fur. Defendia esse autor, que a federação pode surgir de dois modos, vista a seguir conforme as palavras de Azambuja (2005, p. 373):

O Estado Federal pode nascer independentemente de um tratado de dois modos: Quando um Estado, unitário a princípio, se transforma em Estado Federal, ou- 
torgando a suas antigas províncias certa autonomia e concedendo-lhes participação na formação da vontade da União. (AZAMBUJA, 2005, p. 373).

Foi o que aconteceu com o Brasil, pois surgiu como império unitário, transformando-se em República Federativa no ano de 1891. No que concerne ao surgimento, o Estado Federal não é resultado da vontade de particulares, mas sim, objeto da vontade nacional, o que pode ocorrer de modo pacífico ou não.

Podemos destacar, partindo dessa premissa, dois modos diversos de surgimento do federalismo. 0 primeiro é o federalismo por agregação que tem por característica a maior descentralização do Estado, no qual os entes regionais possuem competências mais amplas, como ocorre nos Estados Unidos da América (EUA). O segundo modo de surgimento é o federalismo por desagregação, onde a centralização do Estado é maior, assim, o ente central recebe a maior parcela de poderes, exemplo desse modo, é visto na federação brasileira.

Apesar de partir de um ponto de vista diferente, a Escola de Viena, representada por Kelsen e Verdross, concorda com a Teoria de Le Fur. Tal escola defende que "[...] o Estado Federal determina as ordens jurídicas internas, qualificando de Estados seus membros" (AZAMBUJA, 2005, p. 374). Assim, pode-se afirmar que o Estado Federal representa a órbita internacional, enquanto os Estados Federados representam a órbita interna.

A Confederação norte-americana foi criada pelo Articles of Confederation, se assemelhando ao modelo existente na Grécia Antiga. Todavia, fruto do trabalho Hamilton, Madison e Jay, que criaram uma nova forma de organização territorial, foi que surgiu a Federação.

As confederações eram caracterizadas como uma forma de união de Estados, com a ausência de um poder político único centralizado, ao contrário do que se dava na federação, detentora de poder soberano no círculo das relações internacionais. As atividades das confederações encontravam-se no âmbito externo e, não, em sentido interno. A União, que expressava o poder centralizado, não devia ser investida de todo o poder de elaborar e fazer executar as leis, ficando sua jurisdição limitada a determinados assuntos, que tratavam de todos os membros da república. Os Estados-membros podiam exercer sua autoridade sobre os assuntos que the dissessem respeito com exclusividade, conservando sua competência e atuação. Os autores percebiam claramente que a Confederação, pela qual estavam ligados, era insuficiente para manter a união das treze ex-Colônias. (COSTA, 2012, p. 219).

Por se mostrar ineficaz para garantir a união das treze colônias, os autores do The Federalist Papers fizeram uma longa análise histórica das Confederações formadas anteriormente e demonstraram que essa forma de Estado não satisfazia as necessidades sociais da época. Tratando sobre o assunto, Jardim (1984, p. 55), afirmou que a instituição então formada, era frágil.

Tanto que quando a Inglaterra reconheceu a independência das colônias americanas em 1783, elas quase se extinguiram, uma vez que sua razão de existir praticamente desapareceu. Parafraseando Jardim (1984), tudo conspirava contra a união de tais colônias, afinal, praticamente tudo os separava, e quase nada os unia.

Costa (2012, p. 220), analisando o entendimento de Hamilton, apontava como principal problema surgido com os Articles of Confederation a ausência de sanções quando houvesse desobediência às leis, de modo que o Estado não tinha como punir aqueles que descumprissem o ordenamento jurídico; defendia, ainda, que a Confederação era incapaz de preservar a união, pois tinha apenas força de recomendação e não tinha poder coercitivo. Desta forma, conforme Costa (2012, p. 220):

[...] A grande invenção norte-americana foi justamente a federação, que tinha como característica essencial que os Estados-membros associados não possuíam soberania externa e, quanto à soberania interna, se achavam sujeitos a um poder único, que era o poder federal. Conservavam apenas a autonomia assegurada a sua esfera de competência constitucional, e assim, o Estado federal tinha superioridade legislativa sobre os Estados federados.

O Estado Federal tinha supremacia sobre os Estados Federados, já que a Constituição limitava a atua- 
ção dos ordenamentos jurídicos dos últimos. Importante mencionar que estes não perdiam totalmente sua autonomia, podendo criar e praticar qualquer ato, desde que, não contrariasse o Texto Constitucional.

Conforme Costa (2012, p. 218) "Os Estados Unidos da América, ao se organizarem como federação, deram uma profunda e inovadora forma de como - Estado podia se institucionalizar no território". Além de dar essa nova faceta, foi influenciador de diversas formações posteriores, tais como ocorrida na Alemanha e na Índia. Além disso, influenciou significativamente a formação do Federalismo nos países da América, sendo um dos principais influenciadores para a formação do Federalismo Brasileiro. A principal ferramenta para que isso acontecesse foi a criação da Constituição Federal.

\section{INSTAURAÇÃO DO FEDERALISMO NO BRASIL}

Após a descoberta do território brasileiro pelos portugueses, o Brasil passou a ser dividido administrativamente em capitanias, as quais, em 1821, foram transformadas em províncias. Em 1824 o Brasil tornou-se independente de Portugal e passou a ser governado pelo rei Dom Pedro I, que concentrava em suas mãos todos os atos da administração. Com o passar do tempo, não era mais possível manter essa organização, já que o Brasil se desenvolvia e junto a isso aumentava a necessidade de um modelo de governo que melhor atendesse as necessidades do Brasil que visava progredir em todos os aspectos.

A forma unitária do Estado monárquico era a gênese de uma tradição política centralizadora, fruto do governo colonial, que, após a independência do Brasil, manteve o status centralizador.

Elaborada e outorgada, a Constituição brasileira de 1824 , previa que o governo das províncias seria presidido por pessoas nomeadas pelo imperador. A outro giro, previa que os Conselhos Gerais das Províncias possuíam competências para aprovar normas específicas para gerir os negócios da Província e, além disso, previa o funcionamento das Câmaras dos Distri- tos com competência para gerir a economia dos municípios, prevendo também, a liberdade dos cidadãos de intervir nos negócios da sua localidade, nas Câmaras dos Distritos e nos Conselhos Gerais das Províncias.

Apesar de todas essas medidas adotadas pela constituição de 1824, as elites agrárias regionais pressionavam o governo em virtude do seu centralismo político, tal pressionamento levou o rei Dom Pedro I, em 1831, a abdicar o trono. As pressões continuaram até 1834 quando foi aprovada a Lei $n^{\circ} 16$, de 12 de agosto de 1834, que emendou a constituição do império com o objetivo de torná-la uma monarquia representativa, substituindo os Conselhos Gerais das Províncias por Assembleia Legislativas e implementando princípios federalistas à forma de governo imperial.

A mudança trazida pela Lei $n^{0} 16$ de 12 de agosto de 1834, garantiu funções executivas e legislativas às províncias. No entanto, cada vez mais se exigia descentralização do poder político central, visto que vários movimentos de insatisfação com o poder central surgiram e em 1889 houve a proclamação da república, momento em que o Governo Provisório expediu o Decreto $\mathrm{n}^{\circ} 1$, de 15 de novembro de 1889 , instituindo a federação e, transformando as antigas províncias em Estados-Membros, criando os Estados Unidos do Brazil. Ainda no decreto $n^{\circ} 1$, nos artigos $7^{\circ}$ e $8^{\circ}$ obrigou as antigas províncias, agora transformadas em Estados-membros, a integrarem a nova federação.

Nas palavras de Silva (2014, p. 101):

\begin{abstract}
O Brasil, como vimo, assumiu a forma de Estado federal, em 1889, com a proclamação da República, o que foi mantido nas constituições posteriores, embora o federalismo da Constituição de 1967 e de sua Emenda 1/69 tenha sido apenas nominal. A Constituição de 1988 recebeu-a da evolução histórica do ordenamento jurídico. Ela não instituiu a federação. Manteve-a mediante a declaração, constante no art. $1^{\circ}$, que configura o Brasil como uma República Federativa.
\end{abstract}

A primeira constituição elaborada sob a nova forma de governo seria a constituição de 1891, que trazia no seu artigo $1^{\circ}$ a República Federativa como forma de governo e a regra da união perpétua e indissolúvel dos Estados Membro, além e prever no seu 
artigo $6^{\circ}$ a possibilidade de intervenção da União nos entes federados caso algum Estado resistisse à manutenção da federação.

Após comandar a Revolução de 1930 e derrubar o governo de Washington Luís, Getúlio Vargas assumiu o poder e passou a governar de forma centralista. Getúlio instaurou o Decreto n 19.398 de 11 de novembro de 1930, que dissolveu o Congresso Nacional, as Assembleias Legislativas Estaduais e as Câmaras Municipais, cassou os mandatos de todos os governadores e prefeitos e nomeou interventores em cada Estado-Membro, que por sua vez poderia nomear interventores para governar os municípios.

Apesar de todo o centralismo contido no Decreto $n^{\circ} 19.398$, as constituições e as leis estaduais continuaram em vigor, houve até um reforço da autonomia financeira dos Estados-Membros.

Sob o governo de Getúlio Vargas, foi promulgada a Constituição de 1934, porém em 1937 ele fecha o Congresso Nacional e instala o Estado Novo, passando a governar com poderes ditatoriais. Logo em seguida outorgou a Constituição de 1937, a qual restringia não só as liberdades políticas, como também liberdades de expressão, principalmente as que tinham ideias contrárias ao seu governo.

Vargas saiu do poder em 1945 após um golpe militar, e o Brasil teve, em 1946, uma nova constituição que devolveu aos Estados membros as suas autonomias administrativas e políticas. No entanto, tal autonomia fora usurpada novamente com o Golpe Militar de 1964, que implantou uma ditadura e outorgou a constituição de 1967, mantendo um federalismo meramente nominal, visto que a União concentrava quase a totalidade dos poderes.

Promulgada a Constituição Federal de 1988, buscou-se resgatar o princípio federalista, estruturando um sistema de repartição de competências, tentando refazer o equilíbrio das relações entre o poder central e os poderes estaduais e municipais.

A Constituição de 1988 positivou as garantias de autonomia inerentes aos Estados-Membros em poder de auto-organização, previsto em seu artigo 25 no qual diz: "Os Estados organizam-se e regem-se pelas Constituições e leis que adotarem, observados os princípios desta Constituição". A outra positivação consistiu no poder de autogoverno, previsto nos artigos 27, 28 e 125, que trata dos poderes legislativo, executivo e judiciário, respectivamente, de cada membro da Federação, dando aos Estados a capacidade de organizar o próprio governo, seguindo as orientações da Constituição Federal.

Por fim, observa-se o poder de autoadministração, prevista no artigo $25, \S 1^{\circ}$ que diz: "São reservadas aos Estados as competências que não thes sejam vedadas por esta Constituição."

Ainda, na redação do artigo 60, §4, da CF/88, adota-se o sistema federativo como cláusula pétrea. Não obstante a vedação ao direito de secessão, é plenamente possível que haja reorganização territorial interna, sendo possível o desmembramento de Estados-Membros, cuja autorização resta expressamente prevista no artigo 18, § 2,3 e 4 da CF/88.

É significante destacar que a federação brasileira é denominada de federação centrífuga, também chamada de federação por segregação ou federação às avessas. Esse tipo de federação se deu por um movimento centrífugo, tendo origem em um Estado Unitário que se fragmentou num movimento de dentro para fora. A regra nas federações é um federalismo de primeiro grau, em que a federação declina da União para os Estados-Membros. Já a federação brasileira é considerada uma federação de segundo grau, isto porque além da União e dos Estados-Membros, temos o distrito federal e os municípios.

\section{ANÁLISE COMPARATIVA ENTRE 0 FEDERALISMO BRASILEIRO E O FEDERALISMO NORTE-AMERICANO}

O federalismo brasileiro foi diretamente inspirado no federalismo norte-americano, no entanto guarda com este, substanciais diferenças. Inicialmente, em relação à origem, a república federativa norte-ame- 
ricana foi constituída a partir da união de unidades políticas que detinham soberania, mas que, com o objetivo de fortificar politicamente as antigas colônias inglesas, decidiram unir-se, transferindo a soberania para um ente central. De outra forma ocorreu no Brasil, o qual era marcado por um governo imperial unitário, detentor de toda soberania, que passou a descentralizar o poder político-administrativo para os seus estados-membros.

A presente distinção trouxe consequências importantes. A federação norte-americana surgiu a partir de um consenso entre entidades políticas plenamente construídas, de modo que seus quadros, tanto políticos quanto jurídicos, foram desenvolvidos de forma autônoma. Entretanto, no Brasil ocorreu o inverso, tendo em vista que o ente central já possuía o seu sistema de governo, porém, precisou adaptar esse sistema para que fosse possível conferir independência politica-administrativa para os seus estados-membros.

Tal consequência explica o fato do federalismo norte-americano ter se desenvolvido sem afetar a estrutura jurídica de cada Estado, conservando assim as mais importantes características de organização de cada um deles. Nesse sentido, se faz bem a análise da diversidade observada na adoção de certos posicionamentos, como por exemplo, a institucionalização da pena de morte, que ocorre apenas em parte dos Estados norte-americanos, não sendo norma de aplicabilidade geral para todos os estados que integram a federação norte-americana.

Esse é um fenômeno que afeta bastante a esfera jurídica da federação, sendo que no Brasil, não há essa diversidade de posicionamento, pois as disposições impostas pelo ente central subordinam todos os Estados-membros. Desta forma, o federalismo brasileiro, neste ponto, pode ser considerado como apenas um federalismo político-constitucional. Ademais, o federalismo brasileiro fica restrito basicamente ao plano da cidadania e do regime político, de modo que a organização praticamente permaneceu como sendo de um Estado unitário, cedendo apenas uma pequena autonomia constitucional para aos Estados-membros.

Sem dúvidas, a diferença mais relevante entre os sistemas brasileiro e norte-americano reside na relação entre os Estados-membros da federação e o poder central. Nos EUA, a relação entre Estados-membros e o poder central é bem menor que no Brasil, já que, nos EUA cada Estado atua de forma autônoma e participa das decisões a nível nacional de forma distinta, devido à herança do Federalismo Dual e o laissez-faire. Já no Brasil, caracteriza-se o chamado Federalismo de Cooperação, onde os Estados possuem uma maior tendência a atuarem em conjunto para tratarem de decisões a nível federal.

Outra consequência importante de tal fenômeno é a organização política do território brasileiro em regiões, o que não ocorreu nos EUA, em virtude deste já possuir seus Estados territorialmente delineados. Embora o poder central nos EUA tenha sofrido, nesses últimos tempos, maior centralização, ainda é notória a ampla independência dos Estados em relação à esfera federal quando comparado ao Brasil.

\section{CONSIDERAÇÕES FINAIS}

Após a análise do federalismo norte-americano, restou evidente que foi nos EUA que a forma de Estado federalista, de fato, se materializou, sendo o fruto das ideias de vários pensadores, dentre os quais destacamos Alexander Hamilton, James Madison e John Jay.

Conforme tudo que foi mencionado no presente trabalho, vimos que nem todos os Estados federados possuem a mesma organização político-administrativa. Exemplo disso resta demonstrado quando se faz uma análise comparativa entre o federalismo brasileiro e o norte-americano, pois, enquanto este é uma federação por agregação, aquele é uma federação por segregação, tendo, tal diferenciação, reflexos no que tange a esfera política e administrativa do Estado federado.

Ademais, analisamos o surgimento e desenvolvimento do federalismo brasileiro no âmbito constitucional, tendo em 1891 a primeira previsão cons- 
titucional de que o Brasil havia adotado a forma de Estado federalista. Atualmente, o Brasil adota o sistema federativo como cláusula pétrea, tendo tal previsão elencada no artigo $60, \$ 4^{\circ}$, da CF/88, sendo vedado a qualquer Estado-membro o direito de secessão.

\section{REFERÊNCIAS}

AZAMBUJA, Darcy. Teoria geral do estado. 44.ed. São Paulo: Globo, 2005.

BRASIL. Constituição da República Federativa do Brasil de 1988. Diário Oficial [da] República
Federativa do Brasil. Brasília-DF, 6 out. 1998. Disponível em: <http://www.planalto.gov.br/ ccivil_03/constituicao/constituicao.htm >. Acesso em: 2 maio 2016.

COSTA, Nelson Nery. Ciência política. 3.ed. Rio de Janeiro: Forense, 2012.

JARDIM, Torquato Lorena. Aspectos do federalismo norte-americano. Revista Inf. Legisl. Brasília, 1984.

\section{SILVA, José Afonso da. Curso de direito} constitucional positivo. 37.ed. São Paulo: Malheiros, 2014.

\footnotetext{
1 Bacharelando em Direito pela Universidade Tiradentes - UNIT; integrante do Grupo de Pesquisa Educação, Sociedade e Direito - GPESD; $4^{\circ}$ colocado no $15^{\circ}$ Prêmio de Monografia da UNIT (2013); Assistente de Departamento Pessoal no Escritório Marcos Contabilidade; Voluntário do programa PROVIC/UNIT, orientador: Prof. Me. Gustavo Santana de Jesus. E-mail: juniomdadireito@gmail.com

2 Bacharelando em Direito pela Universidade Tiradentes - UNIT. Participante do Grupo de Pesquisa Educação, Sociedade e Direito GPESD; Voluntário do programa PROVIC/UNIT, orientador: Prof. Me. Gustavo Santana de Jesus. E-mail: karloskleiton@hotmail.com

3 Mestre e Doutorando pela Faculdade de Direito da Universidade de Coimbra; Especialista em Direito pela Universidade Federal da Bahia; Professor Assistente I do Curso de Direito da Universidade Tiradentes - UNIT; Advogado filiado á Ordem dos Advogados do Brasil/OAB-SE; Presidente da Associação Acadêmica Itabaianense Tobias Barreto. E-mail: gustavosantana_adv@hotmail.com
} 